\title{
High-Performance Solid-State Lithium-Ion Battery with Mixed 2D and 3D Electrodes
}

David S. Ashby ${ }^{1,3, *}$, Christopher S. Choi ${ }^{1}$, Martin A. Edwards ${ }^{2}$, A. Alec Talin ${ }^{3}$, Henry S. White ${ }^{2}, \&$ Bruce S. Dunn ${ }^{1, *}$,

1Department of Materials Science and Engineering, University of California, Los Angeles, California 90095, USA

2Department of Chemistry, University of Utah, Salt Lake City, Utah 84112, USA

${ }^{3}$ Sandia National Laboratories, Livermore, California 94550, USA

*Corresponding Authors

DAshby@ucla.edu, ChristopherChoi@ucla.edu, Martin.Edwards@Utah.edu, AATalin@sandia.gov, White@Chem.Utah.edu, BDunn@ucla.edu 
A)
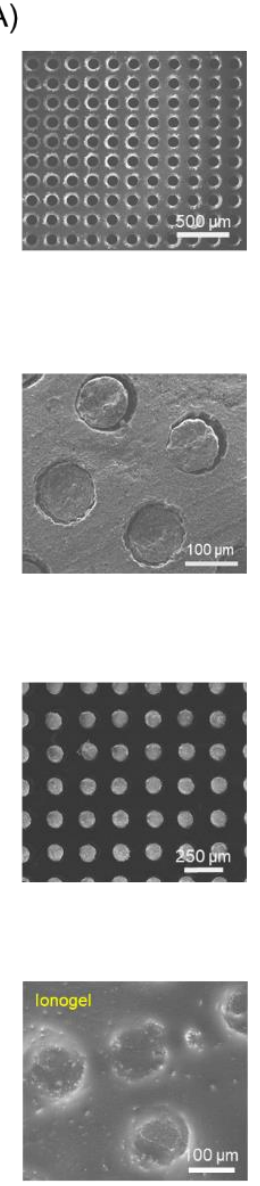

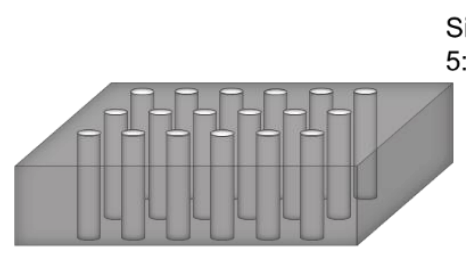

Slurry Infiltration

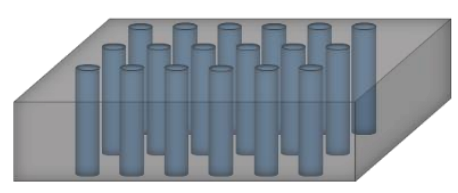

$\mathrm{XeF}_{2}$ Etch

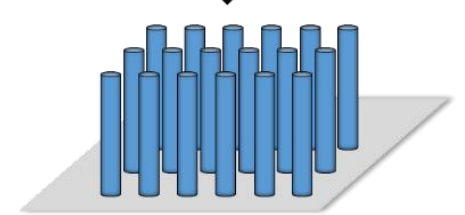

lonogel Fill

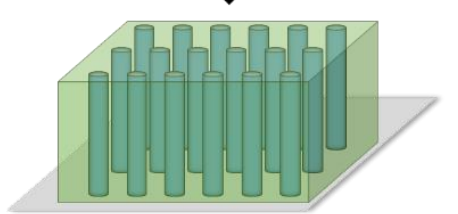

Si Array Mold

$5: 1$ aspect ratio
B)

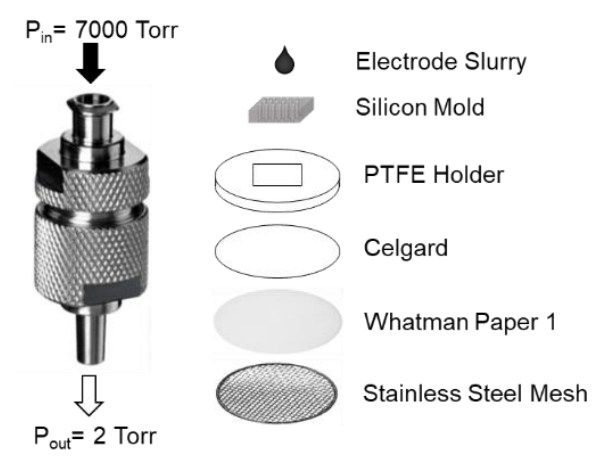

Figure S1: Fabrication process of the 3D cathode array

a) Schematic of the infiltration and template removal process to obtain an infiltrated array. SEM images are provided of the molds/posts at each step of the process with 500,100,250, 100 micron scale bars, respectively. b) Diagram of the high-pressure syringe system used for slurry infiltration. 
a
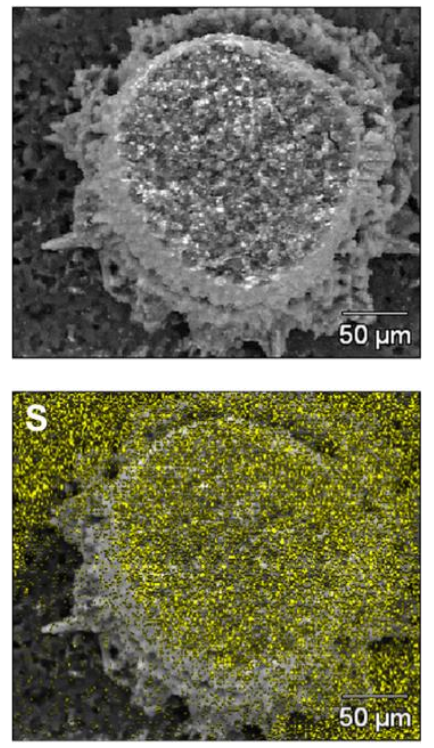
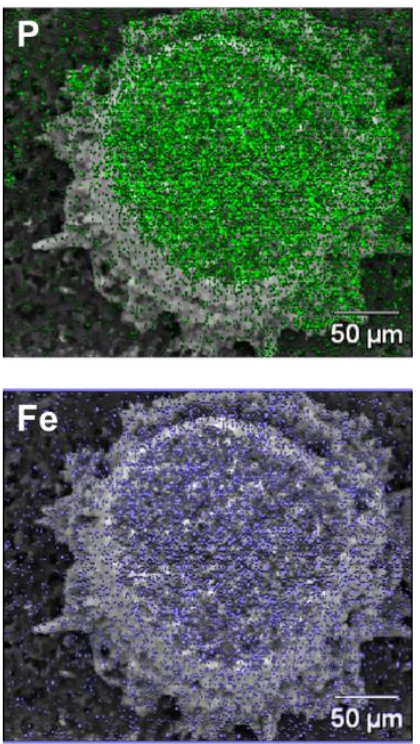

b
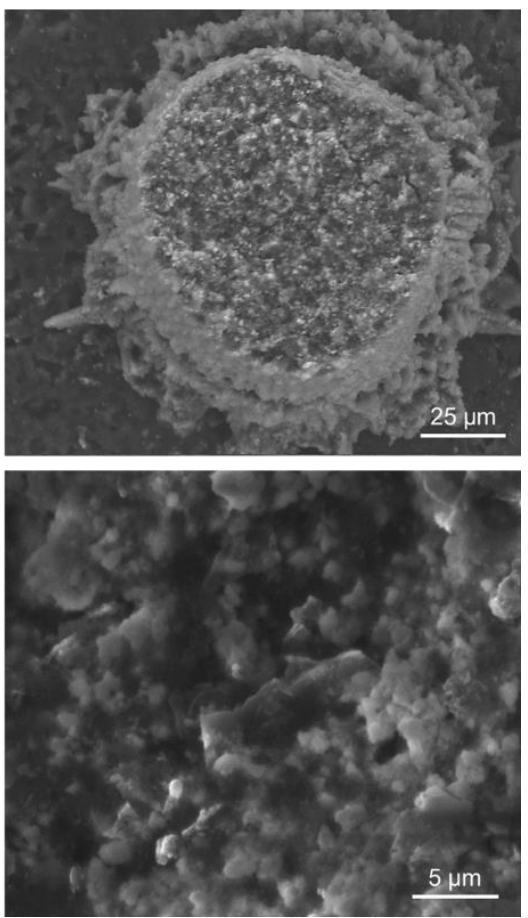

Figure S2: Cross-sectional Analysis of LFP Posts

a) EDS mapping of a SEM cross-section of an ILE-infiltrated LFP array shows the penetration of the ILE component as identified by the sulfur signal. LFP can be identified from the $\mathrm{P}$ and $\mathrm{Fe}$ signals. b) SEM cross-section of an ILE-infiltrated LFP array. A magnified image is provided to demonstrate the porosity. The combination of SEM and EDS shows that the LFP post has a uniform morphology and ILE can infiltrate throughout the array. 

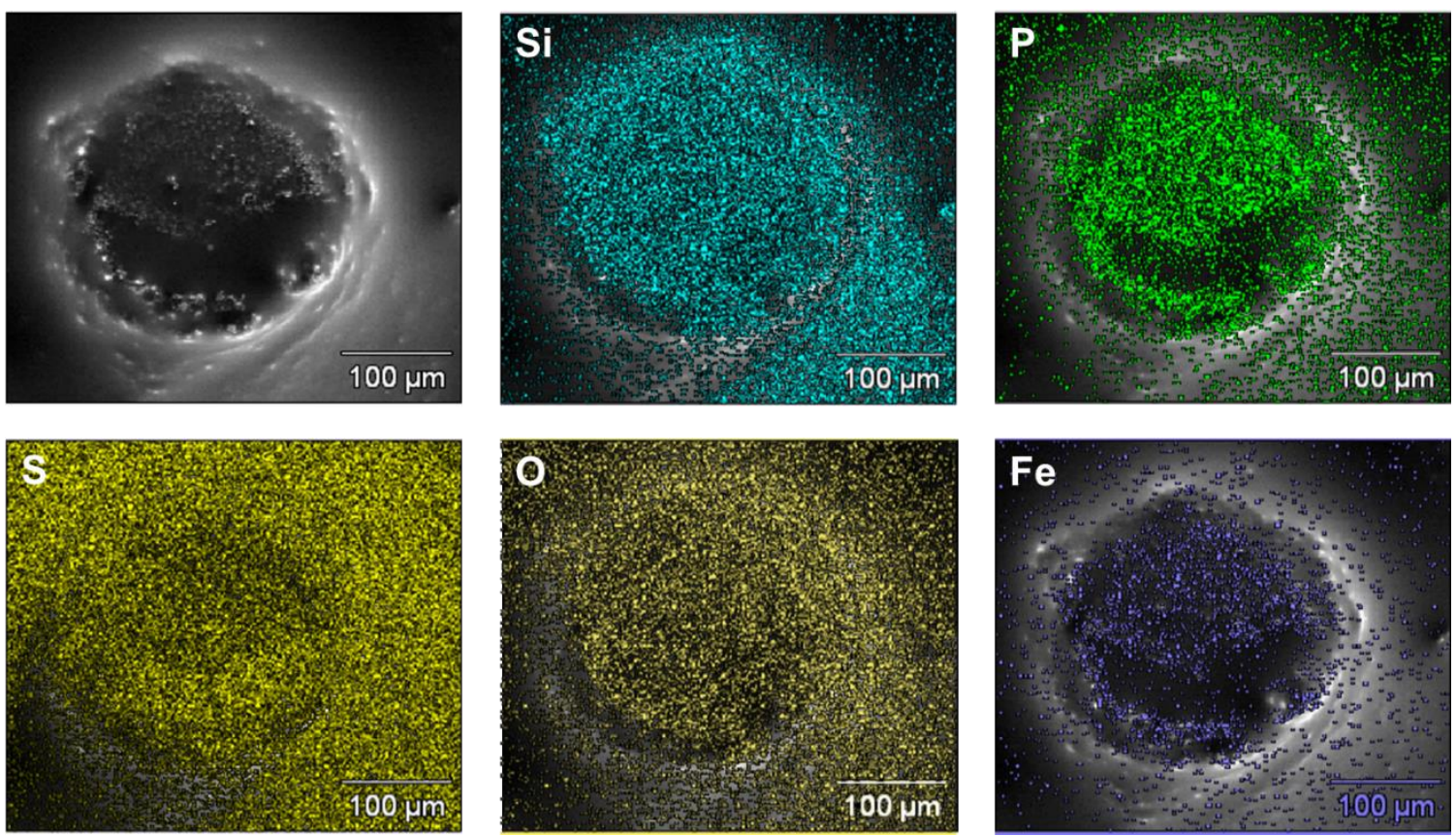

Figure S3: lonogel Penetration in LFP Posts

SEM cross-section of ionogel infiltrated into a single LFP post. EDS mapping shows the penetration of the ILE and $\mathrm{SiO}_{2}$ components, $\mathrm{S}$ and $\mathrm{Si}$ respectively. LFP can be identified from the $\mathrm{P}$ and Fe signals. EDS demonstrates that because of the solution-processability of the ionogel, it is able to infiltrate uniformly through the LFP posts. 
a

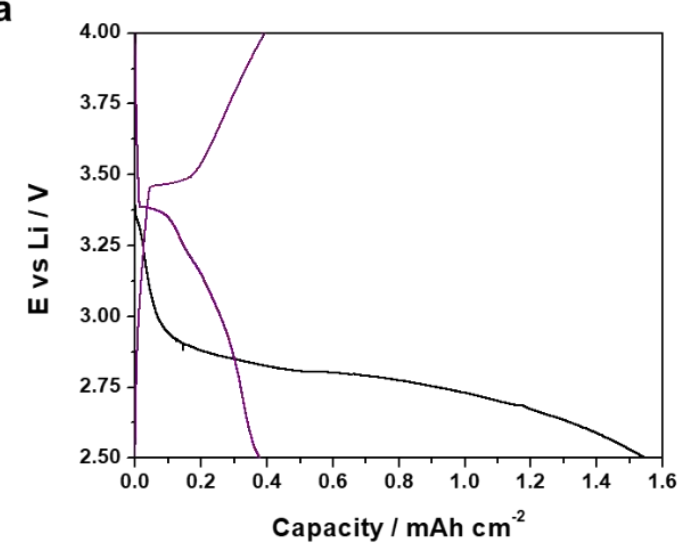

b

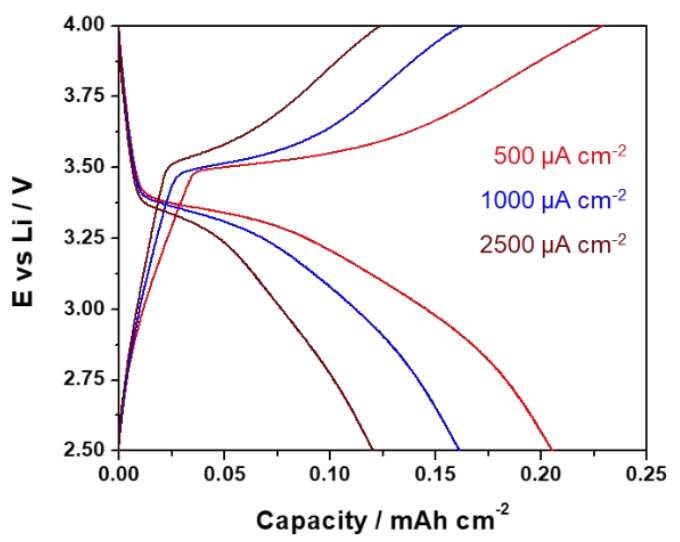

c

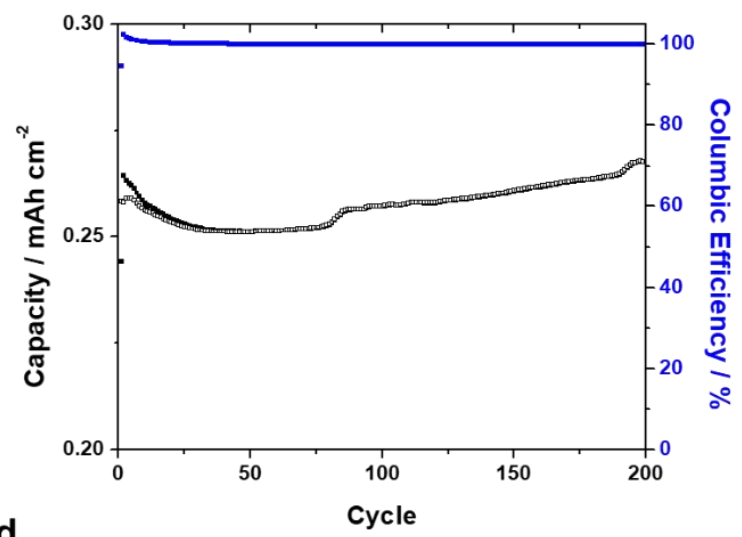

d

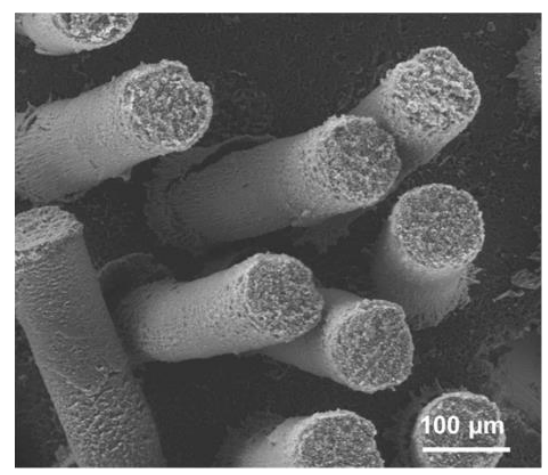

Figure S4: Electrochemical Performance of the 3D Cathode

a) Galvanostatic cycling of the LFP posts in an ILE half-cell for the $1^{\text {st }}$ (black) and $2^{\text {nd }}$ (purple) cycle at $50 \mu \mathrm{A} \mathrm{cm}^{-2}$. b) Galvanostatic cycling of the LFP posts in an ILE half -cell at increasing current density. All cycles correspond to the $3^{\text {rd }}$ cycle at that current density. c) Capacity variation with cycling for the half cell. Cycling stability was performed at $0.5 \mathrm{~mA} \mathrm{~cm}^{-2}$. d) SEM imaging of the LFP posts after cycling. Posts were rinsed with $\mathrm{MeOH}$ before imaging.

The cycling shows a high initial OCV $(3.5 \mathrm{~V})$ and essentially zero capacity from the posts in the initial charge. This most likely is associated with delithiation of the system from the $\mathrm{XeF}_{2}$ processing step. During discharge, a capacity of $1.55 \mathrm{mAh} \mathrm{cm}^{-2}$ was obtained, which is close to theoretical values calculated from the post density and geometry $\left(1.78 \mathrm{mAh} \mathrm{cm}^{-2}\right)$, but at a lithiation voltage much lower than expected for LFP. After the first cycle of the posts in ILE, the capacity retention reduces to $25 \%$ of the first cycle $\left(0.375 \mathrm{mAh} \mathrm{cm}^{-2}\right)$, but the cell does maintain satisfactory rate capability. SEM imaging of the posts after cycling in ILE shows post fracture (Figure S4d), which helps explain the low capacity achieved after the first cycle. It is unclear why the fracture occurred with relithiation as LFP is known to have a low volume change during cycling (6.7\%). ${ }^{1}$ Subsequent cycling of the array for 200 cycles shows a stable capacity indicating that, after the initial lithiation step, the surviving posts are mechanically stable (Figure S4c). 
a

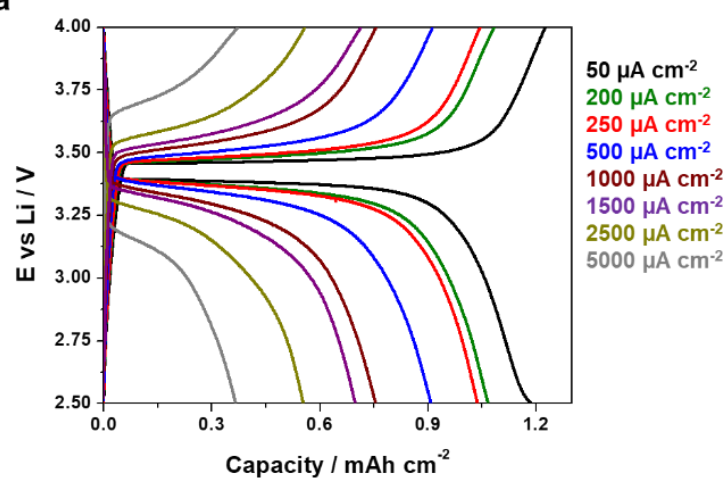

b

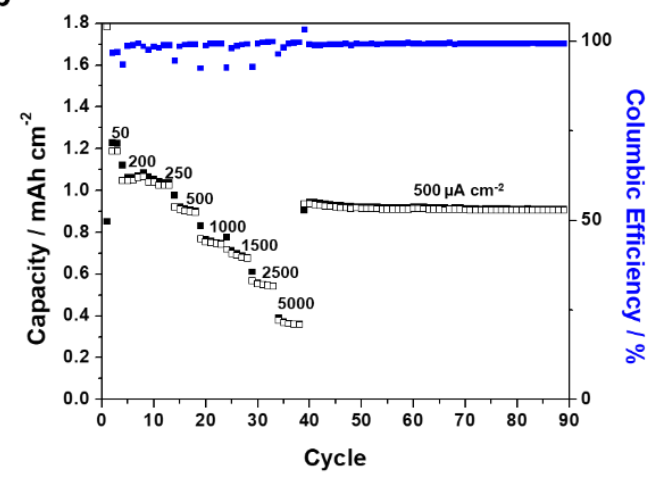

Figure S5: Electrochemical Performance of 2.5D Half Cells

a) Galvanostatic cycling of a flooded half-cell in which the working electrode consisted of an ionogel infiltrated in a LFP post array. All cycles correspond to the $3^{\text {rd }}$ cycle at a given current density. b) Capacity variation with cycling for the half cell. Cycling stability was performed at 0.5 $\mathrm{mA} \mathrm{cm}{ }^{-2}$. The open and filled squares correspond to the discharge and charge capacity, respectively.

The cycling suggests that the ionogel provides sufficient mechanical strength to reinforce the posts. This is seen by the improved capacity retention and significantly greater rate capability over the ILE half cell (Figure S4). 
a

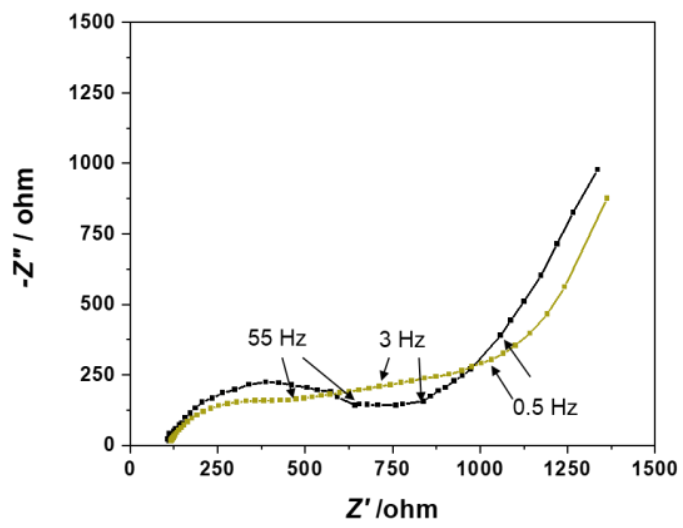

b

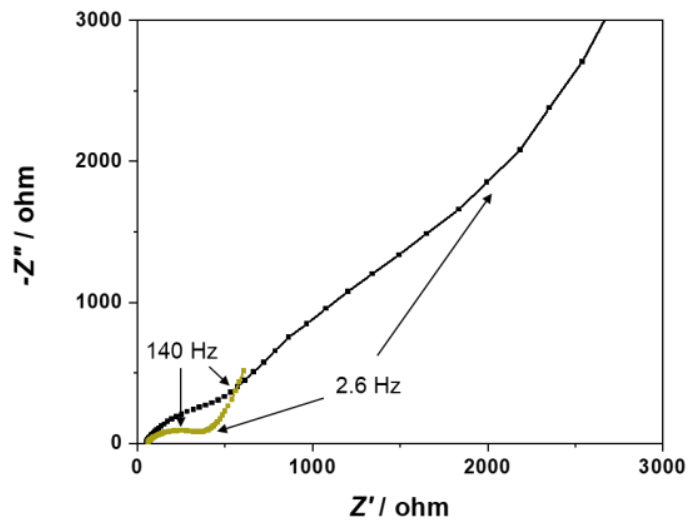

Figure S6: Interfacial Analysis of the 3D Cathode

a) Impedance analysis of the ionogel-infiltrated LFP half-cell before (black) and after the cycling (gold) shown in Figure S5. b) Impedance analysis of the ILE cycled LFP half-cell before (black) and after the cycling (gold) shown in Figure S4. The frequency is provided corresponding to the interfaces.

EIS measurements indicate that the initial interfacial resistances decrease after cycling. The data suggests the interfaces are likely related to the LFP charge transfer resistance $(55 \mathrm{~Hz})$ and a lithium-fluorine compound that forms from the $\mathrm{XeF}_{2}$ etch $(3 \mathrm{~Hz})$. The decrease in the charge transfer resistance with cycling can be attributed to relithiation of the LFP. The decrease in the interface resistance $(3 \mathrm{~Hz})$ can be associated with dissolution of the fluorine compound after prolonged exposure to the ionogel sol as $\mathrm{LiF}$ is soluble in the ionogel sol.

Impedance spectroscopy of the freestanding cathode demonstrates that a large interfacial barrier exists most likely due to the formation of lithium fluoride species from the $\mathrm{XeF}_{2}$ etch (2.6 $\mathrm{Hz}$ ). After cycling, the resistance associated with the fluorine dramatically decreases. This change in resistance correlates well to the large change in polarization between the $1^{\text {st }}$ and $2^{\text {nd }}$ cycle. It is unclear whether this is due to a change in the electrode area fro $\mathrm{m}$ post fracture or from dissolution of the fluorine species. Similarly, the LFP charge transfer resistance $(140 \mathrm{~Hz})$ is shown to decrease, which matches well to what is seen for the ionogel-infiltrated posts. 

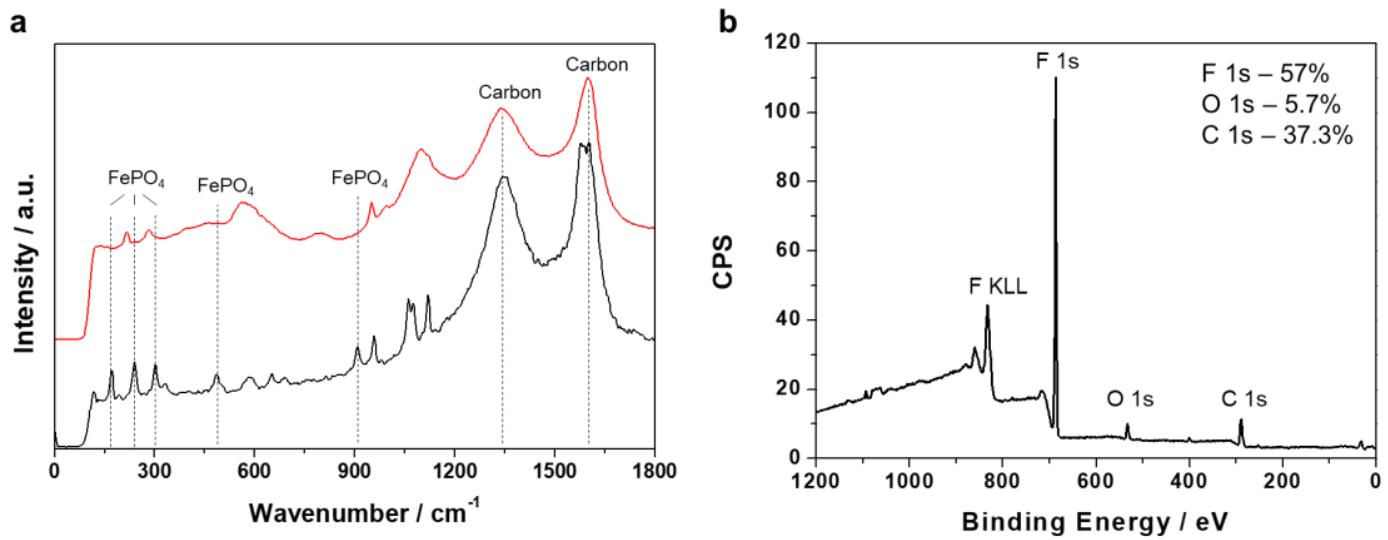

Figure S7: The Effect of Processing Conditions on the 3D cathode

a) Raman analysis of the LFP electrode before (red) and after (black) XeF 2 exposure. (b) XPS analysis of the LFP electrode after $\mathrm{XeF}_{2}$ exposure. The concentration percentages of the identified elements are provided. The spectroscopic data indicates that the $\mathrm{XeF}_{2}$ etch is delithiating the LFP and producing a fluoride layer on the surface which has limited the cycling performance.

The data suggests that the system became delithiated after exposure to $\mathrm{XeF}_{2}$ forming $\mathrm{FePO}_{4}$, which explains the low capacity in the first cycle. All unidentified Raman peaks in the spectrum are associated with $\mathrm{LiFePO}_{4}{ }^{2} \mathrm{The}_{\mathrm{XeF}}$ induced delithiation can be explained by formation of $\mathrm{LiF}$ on the surface, which is inactive in Raman spectroscopy. XPS analysis after $\mathrm{XeF}_{2}$ etching could only identify a dominant $F$ signal along with $\mathrm{O}$ and $\mathrm{C}$, which indicates that a surface fluoride layer could be affecting lithium intercalation. As Li has a low signal to noise ratio in XPS, it is difficult to discern whether there is a change in the lithium concentration. 


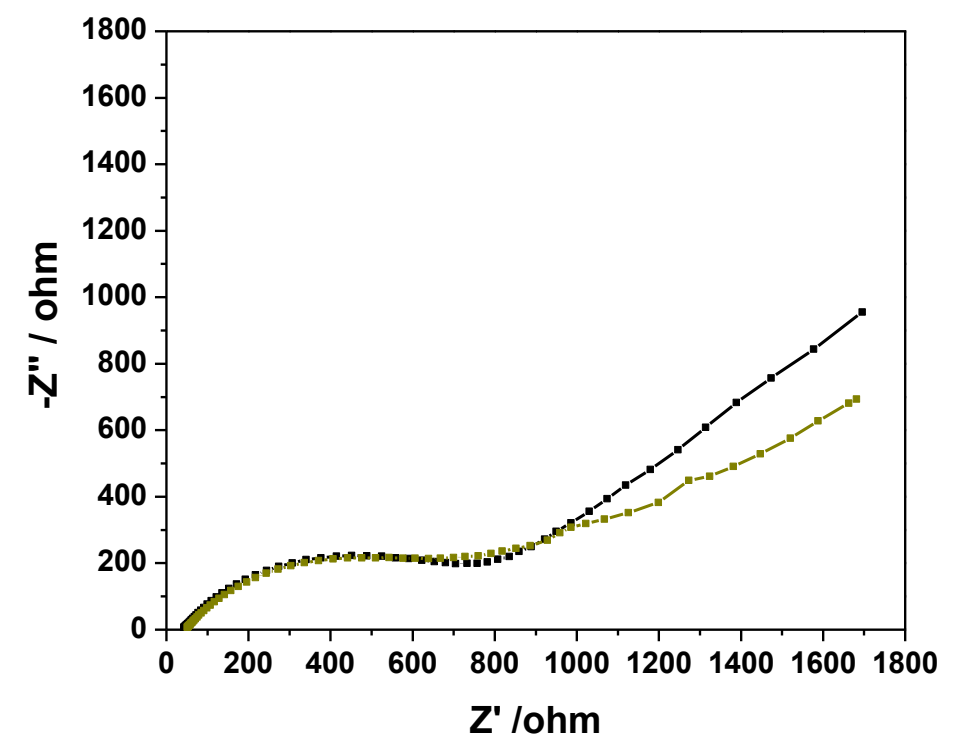

Figure S8: Interface Analysis of a 2.5D Full Cell

Impedance analysis of the infiltrated LFP/Li full cell before (black) and after cycling (gold). See Figure $3 \mathrm{c}$ for the cycling data.

The absence of change in the charge transfer resistance $(800 \mathrm{ohms})$ before and after cycling indicates that the parasitic currents seen during charging (Figure 3c) do not hinder the electrochemical cycling. This is supported by the similar rate capability of the $2.5 \mathrm{D}$ full cell in comparison to the electrochemical cycling of the flooded cell (Figure S5). 


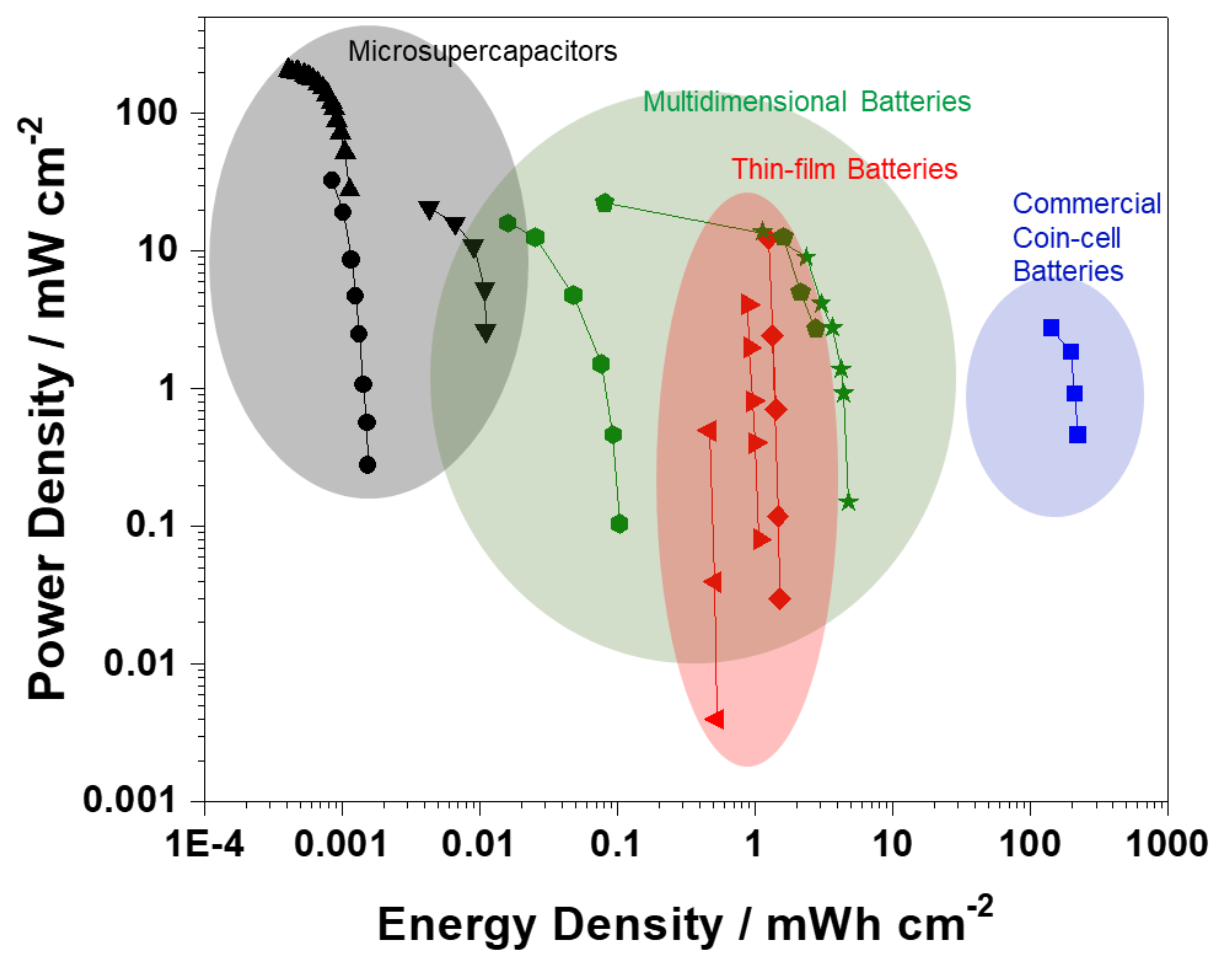

Figure S9: Comparative Ragone Plot of Li-ion Batteries and Microsupercapacitors

Ragone plot comparing multidimensional $\mathrm{Li}$-ion batteries to Li-ion commercial cells, thin-film microbatteries, and microsupercapacitors. The data are listed in Table S2. Both so lid and liquid electrolyte systems are represented. The plot indicates that while multidimensional batteries have improved over laboratory-scale, thin-film batteries, these devices do not possess the areal energy densities comparable to commercial cells. The present work is displayed as the green stars. 


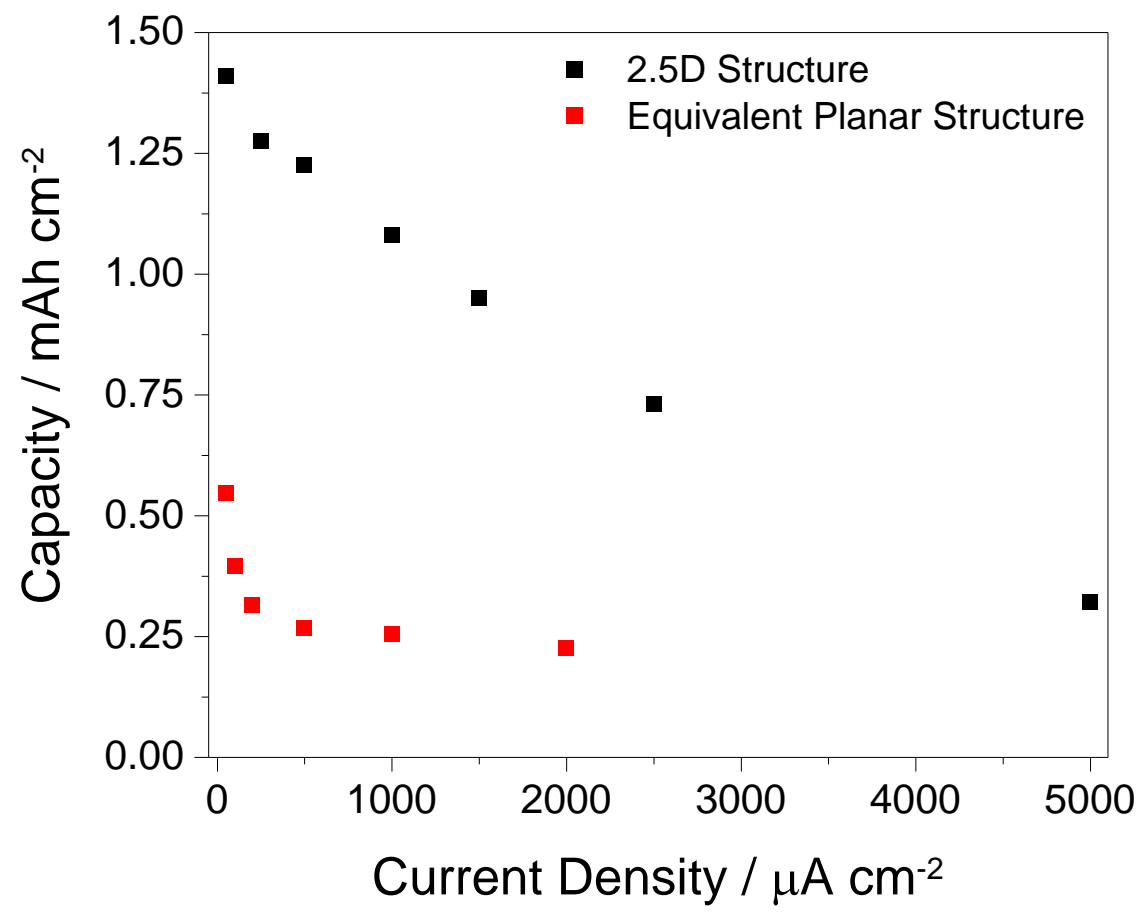

Figure S10: Comparison Between the 2.5D Cell and the Equivalent Planar Architecure

Rate capability comparison of the 2.5D architecture (black, Fig. 3a) to a planar cell with an equivalent areal weight loading. Results for the planar cell were calculated using the developed model (red). There is a significant capacity fall-off in areal capacity with rate for the planar film because of its thickness $(106 \mu \mathrm{m})$. The $2.5 \mathrm{D}$ structure exhibits a more gradual decrease in capacity because the columnar architecture provides a less resistive path and better access to the LFP rods than occurs in a thick 2D slab.

In modeling the 2D cell, finite-element simulations of planar electrodes used identical transport parameters, material properties and charging protocols as those reported for the 2.5D geometries presented in pages S17 - S22. To allow fair comparison, the thickness of the electrolyte is maintained between the two sets of simulations, i.e., the distance from the top of the LFP film to the anode was equal to that from the top of the posts to the anode $(500 \mu \mathrm{m})$. The thickness of the film $(106 \mu \mathrm{m})$ was chosen to contain an identical quantity of cathode material to that included in the 2.5D structures. Due to the symmetry of the problem, it was sufficient to perform this modelling in a 1D geometry as opposed to the 2D axisymmetric geometry used for the $2.5 \mathrm{D}$ array. 


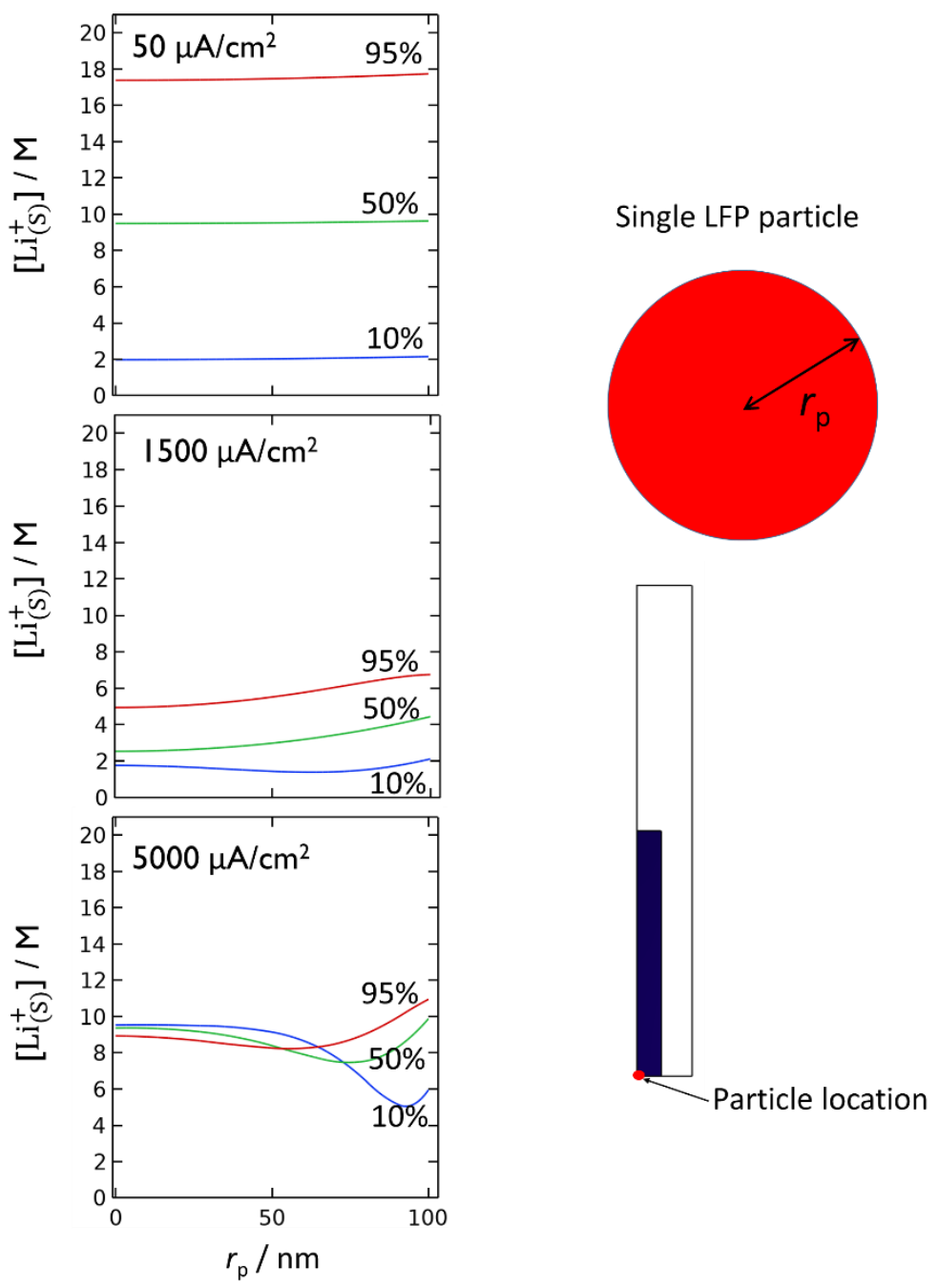

Figure S11: Lithiatiation of the Post Interior

Simulated concentration of $\mathrm{Li}^{+}$within a single particle during discharge at 3 different rates of discharge (as labeled). The inset shows the location at which the particle resides and the coordinate system. The percentages represent the percentage of the total capacity obtained at the given current density. All curves correspond to the $3^{\text {rd }}$ cycle.

The figure provides complementary results to the data provided in Figure 5e which describes lithiation of the post exterior. The data supports the conclusion that the inner regions of the post become lithium deficient at higher current densities, leading to a significant decrease in the capacity. While discharging at $50 \mu \mathrm{A} \mathrm{cm}^{-2}$ achieves almost a $100 \% \mathrm{SOC}$ throughout the particle, at $1500 \mu \mathrm{A} \mathrm{cm}^{-2}$ the particle is only able to achieve approximately $25 \% \mathrm{SOC}$ across the particle. At faster rates $\left(5000 \mu \mathrm{A} \mathrm{cm}^{-2}\right)$, the $\mathrm{Li}^{+}$solid-state diffusion is too slow to achieve redox reactions in the inner $50 \mathrm{~nm}$ of the particle. 

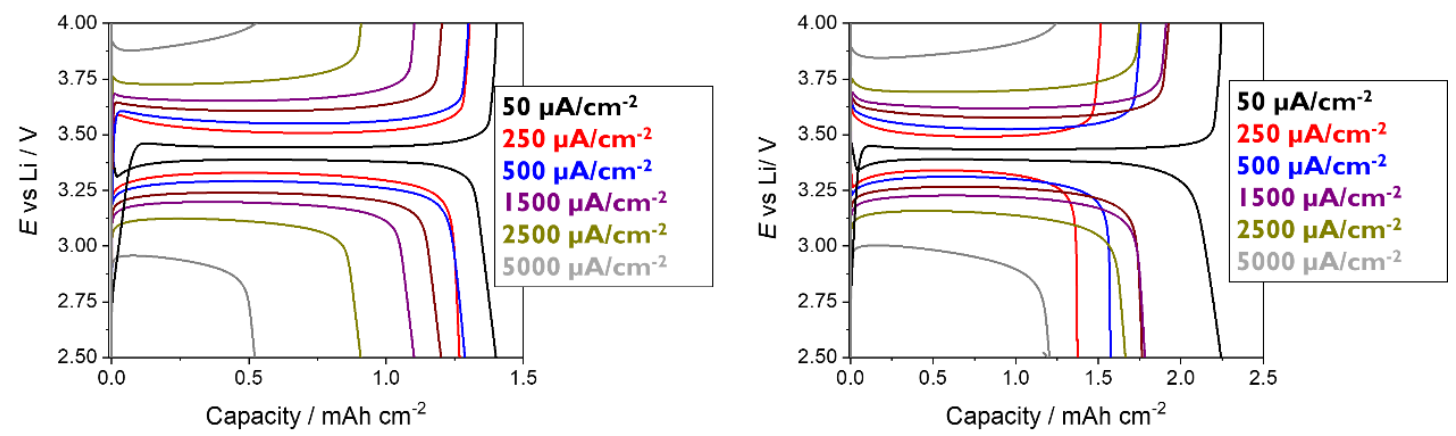

Figure S12: Electrochemical Cycling of Proposed Geometric Variations

a) Simulated galvanostatic cycling for a full 2.5D battery comprised of ionogel infiltrated LFP post/Li full cell with 50-micron diameter posts and a 50-micron pitch. b) Simulated galvanostatic cycling of a full $2.5 \mathrm{D}$ battery comprised of ionogel infiltrated LFP post/Li full cell with 100 -micron diameter posts and a 50-micron pitch.

The simulation shows that by decreasing the post diameter (a), the rate capability can be improved signficantly as a larger portion of the post becomes accessible to lithium intercalation and deintercalation. Similarly, by decreasing the pitch relative to the diameter (b), an increase in capacity is possible, as the number of posts per unit area increases by over $70 \%$. Additional analysis is required to explain the higher capacity achieved at $2500 \mu \mathrm{A} \mathrm{cm}^{-2}$, but this does not diminsh the use of this approach for designing a cell with higher theoretical capacities. 
a

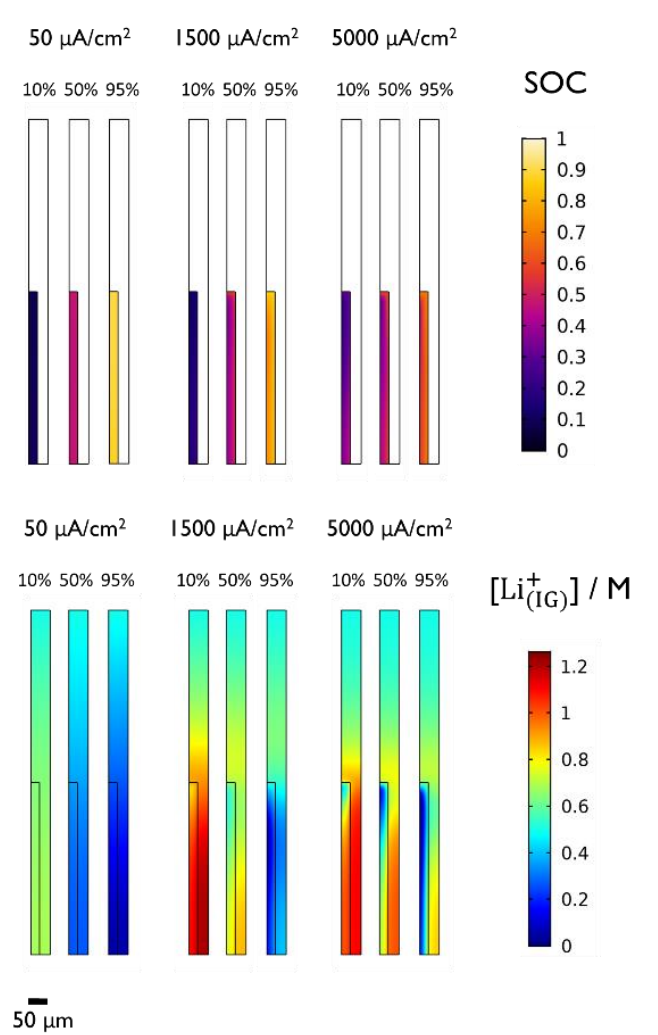

b
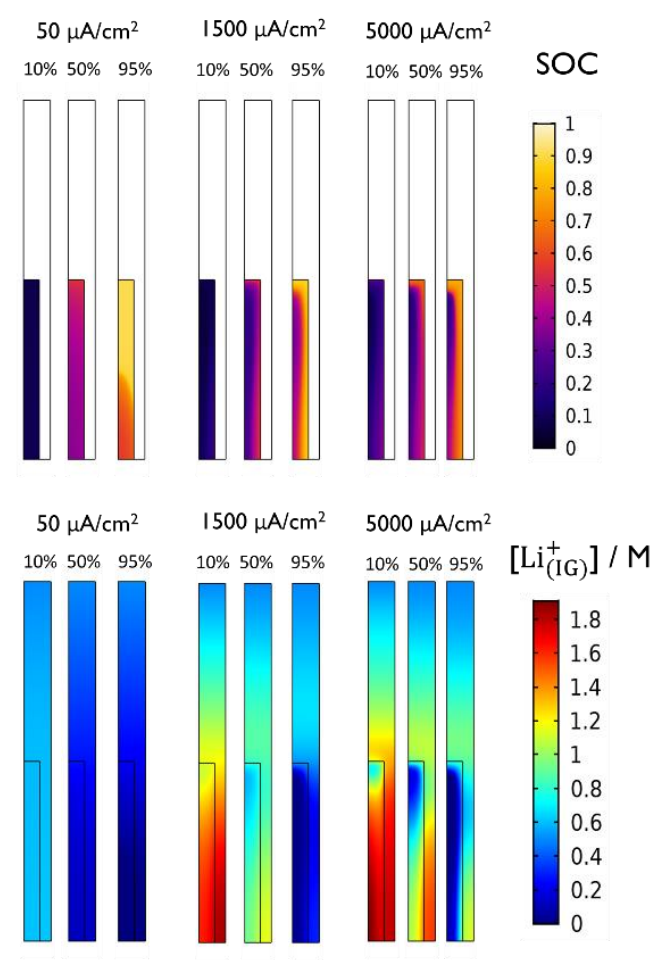

$\overline{100 \mu \mathrm{m}}$

Figure S13: COMSOL Modeling of the Array Geometric Variations

a) Average state of charge of the 50-micron posts with a 50-micron pitch as extracted from the discharge curves reported in Figure $\mathrm{S} 12 \mathrm{a}$ (upper figure). Complementary concentration of $\mathrm{Li}^{+}$in the ionogel electrolyte, including that within the porous electrode, for identical discharge rates and states of discharge (lower figure). b) Average state of charge of 100-micron posts with a 50micron pitch as extracted from the discharge curves reported in Figure $512 b$ (upper figure). Complementary concentration of $\mathrm{Li}^{+}$in the ionogel electrolyte, including that within the porous electrode, for identical discharge rates and states of discharge (lower figure).

Comparison of the state of charge for the two post diameters is consistent with our conclusion that decreasing the post diameter enables the entire post to fully undergo lithiation and delithiation reactions, even at fast discharges. This supports the $167 \%$ increase in capacity at $5000 \mu \mathrm{A} \mathrm{cm}^{-2}$ for the 50-micron posts (Figure S12a) compared to the 100-micron posts (Figure 3a). Both geometries demonstrate that decreasing the pitch between posts does not limit the $\mathrm{Li}^{+}$ transport. By halving the pitch in future designs, the theoretical capacity can be increased from approximately 1.8 to $3.1 \mathrm{mAh} \mathrm{cm}^{-2}$ (Figure S12b). Further analysis is required to explain the increase in the performance for the 100/50 micron geometry. 
Table S1: 3D Batteries Electrochemical Performance

\begin{tabular}{|c|c|c|c|c|c|c|c|}
\hline Electrodes & $\begin{array}{l}\text { Electrode } \\
\text { Geometry }\end{array}$ & $\begin{array}{l}\text { Electrode Height } \\
\text { (um) }\end{array}$ & Aspect Ratio & Electrolyte & $\begin{array}{l}\text { Capacity } \\
\left(\text { mAh } \mathrm{cm}^{-2}\right)\end{array}$ & $\begin{array}{c}\text { Charge Rate } \\
\left(\mathrm{mA} \mathrm{cm}^{-2}\right)\end{array}$ & Reference \\
\hline LFP/Li & Pillar & 500 & 5 & lonogel & $\begin{array}{c}1.4 \\
0.75\end{array}$ & $\begin{array}{c}0.05 \\
2.5\end{array}$ & This Work \\
\hline LFP/Li & Pillar & 500 & 10 & lonogel & $\begin{array}{c}2.25 \\
1.2\end{array}$ & $\begin{array}{c}0.05 \\
5 \\
\end{array}$ & Theoretical \\
\hline NCA/Si & Pillar & 400 & 4 & SU8 & $\begin{array}{l}2.8 \\
0.5 \\
\end{array}$ & $\begin{array}{l}0.11 \\
0.66\end{array}$ & [27] \\
\hline LCO/LTO & 3D printed & 30 & 1.5 & PMMA/LiCIO4 & $\begin{array}{l}0.270 \\
0.170 \\
\end{array}$ & $\begin{array}{c}0.420 \\
2.65 \\
\end{array}$ & [20] \\
\hline $\mathrm{MoS}_{\mathrm{y}} \mathrm{O}_{\mathrm{x}} / \mathrm{MCMB}$ & Polymer Array & 500 & 10 & $\mathrm{SiO}_{2} /$ Kynar & $\begin{array}{c}1 \\
0.6 \\
\end{array}$ & $\begin{array}{c}0.2 \\
1\end{array}$ & [31] \\
\hline V2O5/SnOx & Silicon Array & 300 & 10 & LiPON & $\begin{array}{c}0.02 \\
0.0035\end{array}$ & $\begin{array}{c}0.10 \\
10 \\
\end{array}$ & [28] \\
\hline LCO/Si & Si Cone Array & 4 & 2.5 & LiPON & $\begin{array}{l}0.025 \\
0.003\end{array}$ & $\begin{array}{c}0.0037 \\
0.028\end{array}$ & [8] \\
\hline $\mathrm{LCO} / \mathrm{Li}$ & Thin Film & 2.5 & NA & LiPON & $\begin{array}{l}0.130 \\
0.032\end{array}$ & $\begin{array}{c}0.015 \\
5.25\end{array}$ & [5] \\
\hline $\mathrm{NCM} / \mathrm{Li}$ & Planar Film & 80 & NA & $\beta$-LPS & $\begin{array}{l}1.97 \\
0.83\end{array}$ & $\begin{array}{l}0.36 \\
1.78\end{array}$ & [29] \\
\hline
\end{tabular}

Comparison of the electrochemical performance of Li-ion batteries with non-planar configurations. The planar SSBs, with either a low (5) or high conductivity electrolyte (29) are included as comparisons. The non-planar architectures were fabricated using various techniques. Electrolyte, material loading, and electrode dimensions vary among the reported devices. Results from the current study are indicated in red. The expected performance of a $2.5 \mathrm{D}$ battery with modified dimensions is provided. This result demonstrates that significant improvement is still possible by optimizing the $2.5 \mathrm{D}$ design. References are provided in the main text. 
Table S2: Li-ion Battery and Microcapacitor Electrochemical Comparison

\begin{tabular}{|c|c|c|c|}
\hline Electrodes & Category & Icon & Reference \\
\hline $\mathrm{MnO}_{2} / \mathrm{Li}$ & Commercial Coin Cell & - & [3] \\
\hline LFP/Li & Multidimensional Battery & * & This Work \\
\hline LMO/NiSn & Pillar & $\bullet$ & [10] \\
\hline LFP/LTO & 3D printed & घ & [11] \\
\hline LCO/Li & Thin-Film Battery & $\triangleright$ & [4] \\
\hline LCO/Li & Thin-Film Battery & $\bullet$ & [5] \\
\hline Commercial & Thin-Film Battery & 4 & [6] \\
\hline Onion-like Carbon & Microsupercapacitor & $\boldsymbol{\Delta}$ & [8] \\
\hline Carbide-derived Carbon & Microsupercapacitor & $\bullet$ & [7] \\
\hline $\mathrm{MnO}_{2}$ & Microsupercapacitor & $\boldsymbol{\nabla}$ & [9] \\
\hline
\end{tabular}

List of the liquid-cell multidimensional batteries, coin-cell microbatteries, and interdigitated microsupercapacitors shown in Fig. S9. These devices demonstrate the representative electrochemical performance for different types of architectures and electrochemistry. References are listed below. 


\section{Description of the 2.5D Battery Model:}

To develop a better understanding of the factors affecting the performance of the 2.5D ionogel battery, we developed a numerical model, which describes the coupled ion transport, electrode reactions and electric potentials within the electrolyte and the porous cathode. To keep the model tractable, the precise geometry of each individual particle and pores within the electrode was approximated as a uniform mixture of the substituent components, an approach popularized by Newman. ${ }^{12}$ Throughout the porous cathode, we simulate a LFP phase and interpenetrating ionogel (IG) phases, with electric potential, $\phi_{\mathrm{LFP}}$ and $\phi_{\mathrm{IG}}$, respectively. The fraction, $\epsilon$, of material in each of these two phases $\left(\epsilon_{\mathrm{IG}}=0.35\right.$ and $\left.\epsilon_{\mathrm{LFP}}=0.34\right)$ come from their experimentally determined proportions, with the remainder accounting for the binder, additives, etc. which we treat as an electrochemically inert conductive solid.

The fluxes of the species $i\left(=\mathrm{Li}^{+}, \mathrm{BMIM}^{+}, \mathrm{TFSI}-\right)$, within the ionogel electrolyte are described by the Nernst-Planck equation as

$$
\begin{array}{ll}
J_{i}=-D_{i, \mathrm{IG}} \nabla c_{i, \mathrm{IG}}-\frac{D_{i, \mathrm{IG} F}}{R T} z_{i} c_{i, \mathrm{IG}} \nabla \phi_{\mathrm{IG}} & \text { (ionogel outside cathode) } \\
J_{i}=-D_{i, \mathrm{IG}} \epsilon_{\mathrm{IG}}^{3 / 2} \nabla c_{i, \mathrm{IG}}-\epsilon_{\mathrm{IG}}^{3 / 2} \frac{D_{i, \mathrm{IG}} F}{R T} z_{i} c_{i, \mathrm{IG}} \nabla \phi_{\mathrm{IG}} & \text { (ionogel within the porous electrode) }
\end{array}
$$

where $D_{i, \mathrm{IG}}$ is the effective diffusioncoefficient for species $i$, in the ionogel, $c_{i, \mathrm{IG}}$ is its concentration, $z_{i}$, its charge, $R$ is the molar gas constant, $F$ is Faraday's constant and $T=294 \mathrm{~K}$ is the temperature. $\epsilon_{\mathrm{IG}}^{3 / 2}$ is Bruggeman's relation for transport in packed spheres, which accounts for the longer path the ions must travel around the solid electrode material. ${ }^{44} \mathrm{At}$ the boundary where the porous electrode meets the ionogel electrolyte, the flux, as defined in each expression, is set to be continuous.

We set the initial concentration of the ions in the electrolyte to those of the ionogel as experimentally prepared: $c_{\mathrm{Li}^{+}, \mathrm{IG} \text {,init }}=0.5 \mathrm{M}, c_{\mathrm{BMIM}^{+}, \mathrm{IG} \text {, init }}=3.41 \mathrm{M}$ and $c_{\mathrm{TFSI}^{-}, \mathrm{IG} \text {,init }}=3.91 \mathrm{M}$.

Within the solid phase, we describe transport of lithium $\left(c_{\mathrm{Li}^{+}, \mathrm{LFP}}\right)$ as a diffusional process occurring within spherical particles, which we assume to be of uniform radius, $r_{\text {Particle }}$.

$$
\frac{\partial c_{\mathrm{Li}}+\mathrm{LFP}}{\partial t}=\frac{D_{\mathrm{Li}}+, \mathrm{LFP}}{R_{p}} \frac{\partial^{2}\left(R_{p} c_{\mathrm{Li}}{ }^{+} \mathrm{LFP}\right.}{\partial R_{p}^{2}}
$$

In this description, $D_{\mathrm{Li}^{+}, \mathrm{LFP}}$ is an apparent diffusion coefficient, which encompasses the transport and phase transformation and which we assume to be concentration independent. $R_{p}$ is the coordinate in the radial direction within each particle. At the center of each particle $\left(R_{p}=0\right)$, a no radial flux boundary ensures conservation of $\mathrm{Li}^{+}$and is expressed by:

$$
\left.D_{\mathrm{Li}^{+}, \mathrm{LFP}} \frac{\partial c_{\mathrm{Li}^{+}, \mathrm{LFP}}}{\partial R_{p}}\right|_{R_{p}=0}=0
$$

Within the porous electrode, $c_{\mathrm{Li}^{+}, \mathrm{LFP}}$ and $c_{\mathrm{Li}^{+}, \mathrm{IG}}$ are coupled on the surface of the LFP particles by the intercalation reaction, which occurs at a rate proportional to the local current density, $i_{\text {loc. }}\left(\mathrm{A} / \mathrm{m}^{2}\right)$ (no double-layer charging is considered). This manifests itself in the boundary condition at the LFP particle surface 


$$
\left.D_{\mathrm{Li}^{+}, \mathrm{LFP}} \frac{\partial c_{\mathrm{Li}^{+}, \mathrm{LFP}}}{\partial R_{p}}\right|_{R_{p}=r_{\text {Particle }}}=\frac{i_{\text {loc }}}{F}
$$

and in the mass conservation equation for the electrolyte within the cathode

$$
\frac{\partial \epsilon_{\mathrm{IG}} c_{\mathrm{Li}^{+}, \mathrm{IG}}}{\partial t}=-\nabla \cdot J_{\mathrm{Li}^{+}, \mathrm{IG}}-\frac{i_{\mathrm{loc}}}{F} \times \frac{3 \epsilon_{\mathrm{LFP}}}{r_{\text {particle }}} \quad \text { (ionogel within the porous electrode) }
$$

In this expression, the final term represents the area of LFP particles per unit volume $\left(\mathrm{m}^{-1}\right)$ of the porous electrode.

The continuity equation for the ionogel electrolyte outside the cathode, is as follows, and lacks the final ( $\mathrm{Li}^{+}$source) term

$$
\frac{\partial c_{\mathrm{Li}^{+}, \mathrm{IG}}}{\partial t}=-\nabla \cdot J_{\mathrm{Li}^{+}, \mathrm{IG}} \quad \text { (ionogel outside cathode) }
$$

The local current density is governed by the potentials in the LFP and ionogel phases, the $\mathrm{Li}^{+}$ concentrations at the surface of the LFP particles, which we denote $c_{\mathrm{Li}^{+}}$, surf , the $\mathrm{Li}^{+}$concentration in the electrolyte, and the intrinsic properties of the LFP. We describe the current density using a Butler-Volmer expression

$$
i_{\text {loc }}=i_{0}(\exp (\alpha \eta f)-\exp ((1-\alpha) \eta f))
$$

where $f=F / R T, \alpha$ is the electron transfer coefficients (assumed as 0.5). $\eta=\phi_{\mathrm{LFP}}-\phi_{\mathrm{IG}}-E_{\mathrm{eq}}$ is the overpotential, with $E_{\text {eq }}$ the equilibrium potential, a function of $c_{\mathrm{Li}^{+}, \mathrm{LFP} \text {,surf }}$ as shown in Figure $\mathrm{S} 14$ (data from Kasavajjula et al.) ${ }^{13} \cdot i_{0}\left(\mathrm{~A} / \mathrm{m}^{2}\right)$ is the local exchange current density as described by

$$
i_{0}=i_{0}^{\prime}\left|\frac{\left(c_{\mathrm{Li}^{+}, \text {maxLFP }}-c_{\mathrm{Li}^{+}, \text {surf }}\right)}{c_{\mathrm{Li}^{+}, \text {maxLFP }}} \frac{c_{\mathrm{Li}^{+}, \mathrm{IG}}}{c_{\mathrm{Li}^{+}, \mathrm{IG}, \text { init }}}\right|^{\alpha}\left|\frac{c_{\mathrm{Li}^{+}, \text {surf }}}{c_{\mathrm{Li}^{+}, \text {maxLFP }}}\right|^{\alpha_{c}}
$$

where $c_{\mathrm{Li}^{+}}$,maxLFP $=21.2 \mathrm{M}$ is the maximum concentration of $\mathrm{Li}^{+}$in the LFP and $i_{0}^{\prime}$ is $1 \times 10^{-4} \mathrm{~A} / \mathrm{m}^{2}$. The use of absolute value aids in numerical stability of the model when one of the concentrations approaches zero or $c_{\mathrm{Li}^{+} \text {,surf }}$ approaches $c_{\mathrm{Li}^{+}}$, maxLFP . 


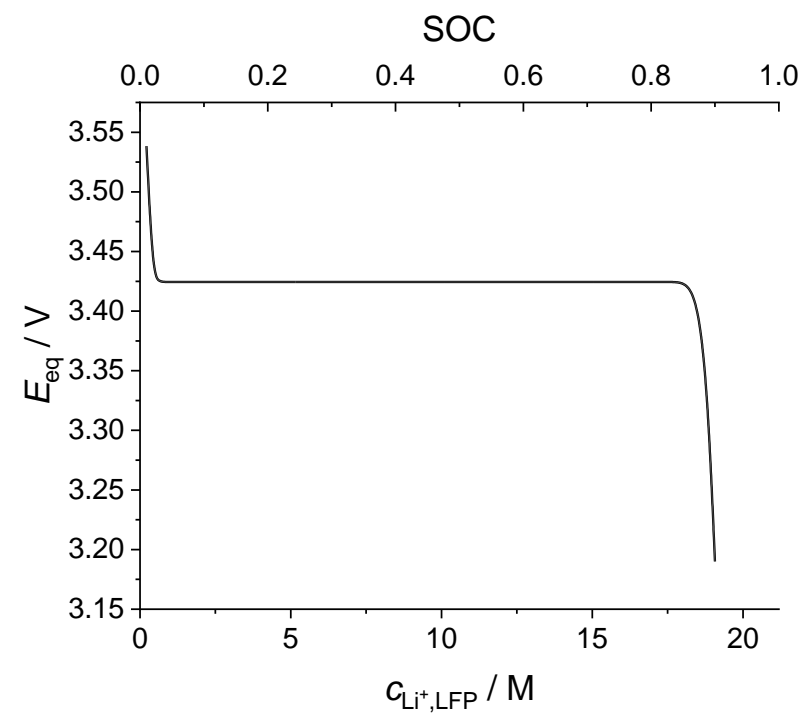

Figure $\mathrm{S} 14$. The equilibrium potential for LFP as a function of $c_{\mathrm{Li}}{ }^{+}, \mathrm{LFP}$ and of state of charge (SOC $=c_{\mathrm{Li}^{+}, \mathrm{LFP}} / c_{\mathrm{Li}}{ }^{+}$,maxLFP $)$

With the high ionic strength, the influence of electric double layers can be neglected and so we used an electroneutrality assumption throughout the electrolyte, that is

$$
0=\sum_{i} z_{i} c_{i, I G}
$$

The current in the ionogel, $i_{\mathrm{IG}}$, arises from the flux of ions, $J_{i}$

$$
i_{\mathrm{IG}}=F \sum_{i} z_{i} J_{i}
$$

where $j_{i}$ is taken from equations $\mathrm{S} 1$ and $\mathrm{S} 2$ in the ionogel within and beyond the cathode, respectively.

Conservation of current dictates that in the ionogel electrolyte beyond the cathode we have

$$
0=\nabla \cdot i_{\mathrm{IG}}
$$

While for the electrolyte within the cathode there is an additional current source/sink term

$$
0=\nabla \cdot i_{\mathrm{IG}}+\epsilon_{\mathrm{IG}} i_{l o c}
$$

Within the solid component of the cathode, we have the equivalent current conservation equation

$$
0=\nabla \cdot i_{\mathrm{s}}-\epsilon_{\mathrm{LFP}} i_{l o c}
$$

where $i_{\mathrm{s}}$ is the current defined as $i_{s}=-\sigma_{S} \nabla \phi_{S}$, where $\sigma_{S}(=1160 \mathrm{mS} / \mathrm{cm})$ is the conductivity of the solid phase (LFP, C, binder, etc.) which was measured experimentally from the conductivity of a post lacking electrolyte. Thus, this number encompasses the different conductivities of all the solid components as well as their connectivity/distribution.

Simulations were performed in domains that describe the planar and 2.5D geometries, while taking advantage of their symmetries to reduce the number of dimensions. For the planar system, a 1-D simulation was sufficient to capture the translational symmetry (Figure S15a), whereas for the $2.5 \mathrm{D}$ battery, we used a 2D-axisymmetric model, which approximates the cuboid unit cell as 
a cylinder of equal cross-sectional area $(100 \times 100 \mu \mathrm{m} \rightarrow 113 \mu \mathrm{m}$ radius $)$ in a 'diffusional domain' type approach ${ }^{14,15}$, shown in Figure S15b. A symmetry argument states that there is no current/species flow between neighboring domains. Edge effects are not considered and are anticipated to be minor.
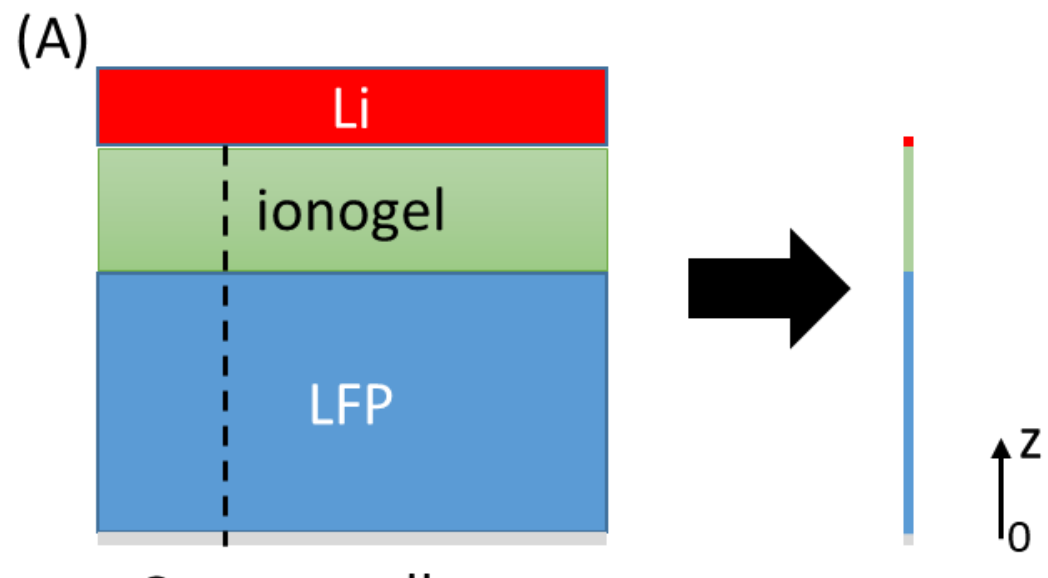

\section{Current collector}

(B)

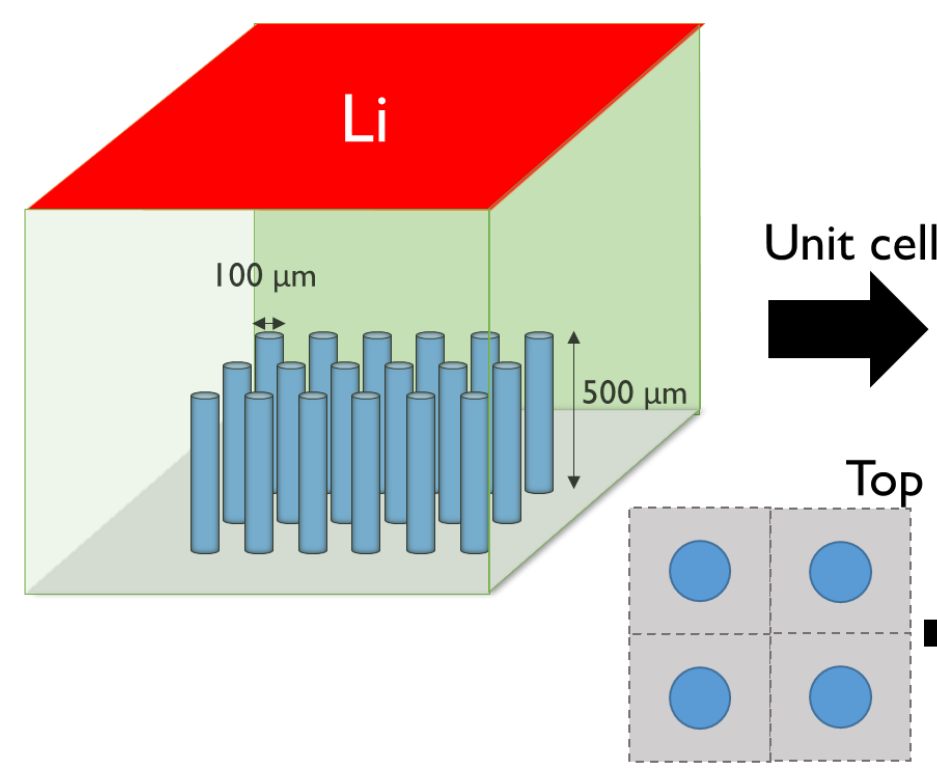

Axial symmetry

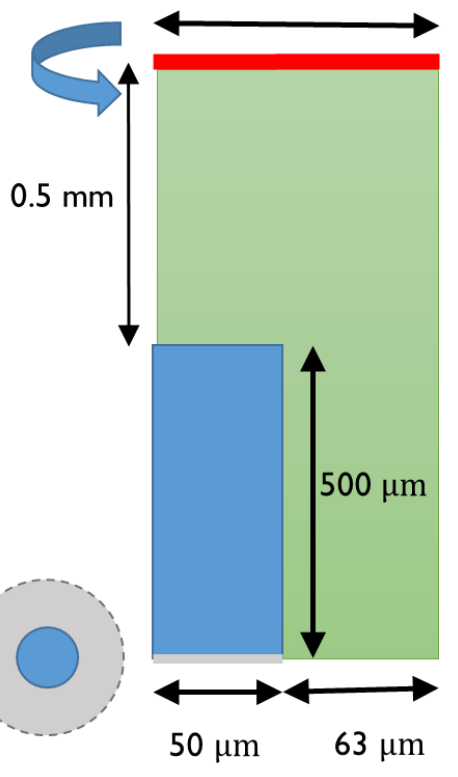

Figure S15. Geometries used for simulations. a) A 1-dimensional cross-section geometry is used to simulate the planar cell. b) A single unit cell (center) from the array of posts (left) is approximated by a single axisymmetric cylindrical geometry of identical area (right).

In the 2.5-D battery, the concentrations of all ionic species at top of the domain were fixed to their initial concentrations, i.e., $c_{i, I G, \text { init }}=c_{i, I G}$, representing an ideal bulk solution and was set to a reference potential of $0 \mathrm{~V}$. No flux of any ion was allowed through any of the other boundaries, 
i.e., $J_{i} \cdot \bar{n}=0$, where $\bar{n}$ represents the unit normal to the surface. For the planar battery boundary conditions were described similarly, but the periodic boundary is absent.

On the current collector at the bottom of the post (grey in Figure S16), the potential was varied to satisfy the requirement that the total current, as measured by the integral $\int i_{s}$, matched that in the experiments when the symmetry (number of posts/active area) was considered.

As in the experiments, the sign on the current was reversed whenever the potential reached 2.5 $\mathrm{V}$ (switched to negative) or $4.0 \mathrm{~V}$ (switched to positive).

The equations were discretized on a mesh such as shown in Figure S16. The mesh was chosen such that further refinement saw no significant change in the simulated response.

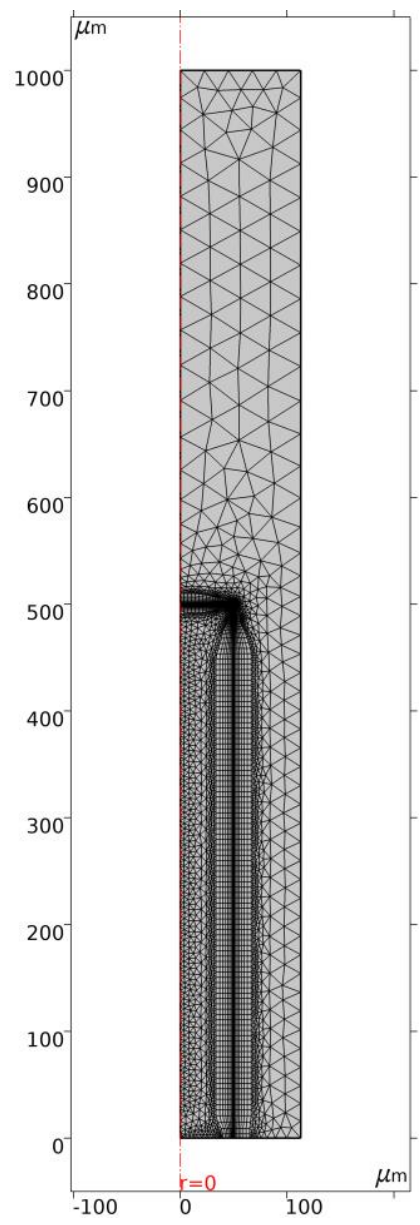

Figure S16. Mesh used for finite element simulations of a 2.5-D ionogel solid-state battery

The model was implemented using the commercial finite-element package, Comsol Multiphysics (version 5.4). The implementation used the tertiary current density component of the Batteries and Fuel Cells module. Lithium diffusion within the particles was described using the weak formulation. The end of each charge/discharge event was detected by using the 'events' functionality. 


\section{Accounting for loss of capacity}

In experimental measurements of the planar battery, the capacity, as determined at low C-rates was $\sim 50 \%$ below that which was calculated from the mass loading of LFP in the slurry from which the cell was formed. In these batteries, flaking of the film was observed, which we believe lead to a disconnection of certain portions of the film. In order to draw comparisons between the model and experiment, we used the experimentally measured capacity to determine the fraction of the film that was disconnected. The applied current density that was applied in simulations was then adjusted to account for the decreased area.

Table S3. Parameters used in the finite element simulations.

\begin{tabular}{|c|c|}
\hline Parameter & Value \\
\hline$c_{\mathrm{Li}^{+}, \mathrm{IG}, \text { init }}$ & $0.5 \mathrm{M}$ \\
\hline$c_{\mathrm{BMIM}^{+}, \mathrm{IG}, \text { init }}$ & $3.41 \mathrm{M}$ \\
\hline$c_{\mathrm{TFSI}^{-}, \mathrm{IG}, \text { init }}$ & $3.91 \mathrm{M}$ \\
\hline ZTFSI- & -1 \\
\hline$Z \mathrm{Li}+$ & +1 \\
\hline ZBMIM+ & +1 \\
\hline$D \mathrm{Li+}, \mathrm{LFP}$ & $2 \times 10^{-14} \mathrm{~cm}^{2} / \mathrm{s}$ \\
\hline$D_{\mathrm{Li}+, \mathrm{IG}}$ & $1.0 \times 10^{-12} \mathrm{~m}^{2} / \mathrm{s}$ \\
\hline$D_{\mathrm{BMIM}+, \mathrm{IG}}$ & $6.3 \times 10^{-12} \mathrm{~m}^{2} / \mathrm{s}$ \\
\hline$D_{\mathrm{TFSI}-\mathrm{IG}}$ & $3.4 \times 10^{-12} \mathrm{~m}^{2} / \mathrm{s}$ \\
\hline$c_{\mathrm{Li}^{+}, \operatorname{maxLFP}}$ & $21.19 \mathrm{M}$ \\
\hline$\epsilon_{\mathrm{IG}}$ & 0.35 \\
\hline$\epsilon_{\mathrm{LFP}}$ & 0.34 \\
\hline$r_{\text {Particle }}$ & $100 \mathrm{~nm}$ \\
\hline$\alpha=\alpha_{a}=\alpha_{a}$ & 0.5 \\
\hline$i_{0}^{\prime}$ & $1 \times 10^{-4} \mathrm{~A} / \mathrm{m}^{2}$ \\
\hline$\sigma_{S}$ & $1160 \mathrm{mS} / \mathrm{cm}$ \\
\hline
\end{tabular}


References:

(1) Awarke, A.; Lauer, S.; Wittler, M.; Pischinger, S. Quantifying the Effects of Strains on the Conductivity and Porosity of $\mathrm{LiFePO}_{4}$ Based Li-Ion Composite Cathodes Using a Multi-Scale Approach. Comput. Mater. Sci. 2011, 50 (3), 871-879. https://doi.org/10.1016/j.commatsci.2010.10.024.

(2) Wu, J.; Dathar, G. K. P.; Sun, C.; Theivanayagam, M. G.; Applestone, D.; Dylla, A. G.; Manthiram, A.; Henkelman, G.; Goodenough, J. B.; Stevenson, K. J. In Situ Raman Spectroscopy of LiFePO4: Size and Morphology Dependence during Charge and Self Discharge. Nanotechnology 2013, 24 (42), 424009. https://doi.org/10.1088/09574484/24/42/424009.

(3) Lithium Coin Handbook and Application Manual Lithium/Manganese Dioxide-Coin (Li/MnO2) Energizer Brands, LLC.

(4) Dudney, N. J.; Jang, Y. II. Analysis of Thin-Film Lithium Batteries with Cathodes of 50 $\mathrm{nm}$ to $4 \mu \mathrm{m}$ Thick $\mathrm{LiCoO}_{2}$. In Journal of Power Sources; Elsevier, 2003; Vol. 119-121, pp 300304. https://doi.org/10.1016/S0378-7753(03)00162-9.

(5) Oukassi, S.; Salot, R.; Bazin, A.; Secouard, C.; Chevalier, I.; Poncet, S.; Poulet, S.; Boissel, J. M.; Geffraye, F.; Brun, J. Millimeter Scale Thin Film Batterie s for Integrated High Energy Density Storage. In Technical Digest - International Electron Devices Meeting, IEDM; Institute of Electrical and Electronics Engineers Inc., 2019; Vol. 2019-December. https://doi.org/10.1109/IEDM19573.2019.8993483.

(6) Rechargeable Solid State Bare Die Batteries EnerChip ${ }^{T M}$ Bare Die Features. Cymbet Corp.

(7) Huang, P.; Lethien, C.; Pinaud, S.; Brousse, K.; Laloo, R.; Turq, V.; Respaud, M.; Demortière, A.; Daffos, B.; Taberna, P. L.; Chaudret, B.; Gogotsi, Y.; Simon, P. On-Chip and Freestanding Elastic Carbon Films for Micro-Supercapacitors. Science (80). 2016, 351 (6274), 691-695. https://doi.org/10.1126/science.aad3345.

(8) Pech, D.; Brunet, M.; Durou, H.; Huang, P.; Mochalin, V.; Gogotsi, Y.; Taberna, P. L.; Simon, P. Ultrahigh-Power Micrometre-Sized Supercapacitors Based on Onion-like Carbon. Nat. Nanotechnol. 2010, 5 (9), 651-654. https://doi.org/10.1038/nnano.2010.162.

(9) Eustache, E.; Douard, C.; Demortière, A.; De Andrade, V.; Brachet, M.; Le Bideau, J.; Brousse, T.; Lethien, C. High Areal Energy 3D-Interdigitated Micro-Supercapacitors in Aqueous and Ionic Liquid Electrolytes. Advanced Materials Technologies. 2017. https://doi.org/10.1002/admt.201700126.

(10) Ning, H.; Pikul, J. H.; Zhang, R.; Li, X.; Xu, S.; Wang, J.; Rogers, J. A.; King, W. P.; Braun, P. V. Holographic Patterning of High-Performance on-Chip 3D Lithium-lon Microbatteries. Proc. Natl. Acad. Sci. 2015, 112 (21), 6573-6578.

https://doi.org/10.1073/pnas.1423889112.

(11) Sun, K.; Wei, T.-S.; Yeop Ahn, B.; Yoon Seo, J.; Dillon, S. J.; Lewis, J. A. 3D Printing of Interdigitated Li-lon Microbattery Architectures. Adv. Mater. 2013, 25, 4539-4543.

https://doi.org/10.1002/adma.201301036. 
(12) Bruggeman, D. A. G. Berechnung Verschiedener Physikalischer Konstanten von Heterogenen Substanzen. I. Dielektrizitätskonstanten Und Leitfähigkeiten Der Mischkörper Aus Isotropen Substanzen. Ann. Phys. 1935, 416 (7), 636-664. https://doi.org/10.1002/andp.19354160705.

(13) Kasavaijula, U. S.; Wang, C.; Arce, P. E. Discharge Model for LiFePO 4 Accounting for the Solid Solution Range. J. Electrochem. Soc. 2008, $155(11), 866$. https://doi.org/10.1149/1.2980420.

(14) Amatore, C.; Savéant, J. M.; Tessier, D. Charge Transfer at Partially Blocked Surfaces. A Model for the Case of Microscopic Active and Inactive Sites. J. Electroanal. Chem. 1983, 147 (1-2), 39-51. https://doi.org/10.1016/S0022-0728(83)80055-2.

(15) Godino, N.; Borrisé, X.; Muñoz, F. X.; del Campo, F. J.; Compton, R. G. Mass Transport to Nanoelectrode Arrays and Limitations of the Diffusion Domain Approach: Theory and Experiment. J. Phys. Chem. C 2009, 113(25), 11119-11125. https://doi.org/10.1021/jp9031354. 